\title{
Road Traffic Control System in Cloud Computing: A Review
}

\author{
${ }^{1}$ Kapil Kumar and ${ }^{2}$ Dr. Pankaj Deep Kaur \\ 1,2 Department of Computer Science and Engineering \\ Guru Nanak Dev University Regional Campus Jalandhar, INDIA \\ ${ }^{1}$ Email:er_kapilkumar@yahoo.com \\ ${ }^{2}$ Email:pankajdeepkaur@gmail.com
}

\begin{abstract}
Road traffic on public roads around the world is a vital problem and is seemly a major pretend to conclusion makers. Urban region have a great stack of traffic jams. Many superimposed concepts of road traffic Gas lit, Wireless sensor networks have appeared in the past few years. The living methods for traffic management are not effective. At that place require for a hefty and scalable high-execution computing. Cloud computing is turning a good engineering to provide a potent and scalable computing at low cost. Therefore Sensor-Cloud is seemly popular in recent years. This paper attempts to review these concepts and discusses their ending alignment with other phase of networks like Sensor-cloud network. The key obstructions to the successful acceptance of Sensor-could have been distinguished and directions for the existing and finally the conclusion have been discussed.
\end{abstract}

Keywords: Cloud Computing, Sensor-cloud Network, Gas Lit, Wireless Sensor Network, Virtualization

\section{Introduction}

Traffic over-crowding is a critical trouble in many urban centers across the universe. The existing methods are not accurate in terms of performance and cost for traffic management and control. Urban region have a more problem of traffic crushes, particularly when a bit of conjunctions take into thoughtfulness. [1].

The traffic signal is typically controlled by a controller inside a cabinet climbed on a concrete grid. Some electro-mechanical controllers are still in use [2]. Traffic control will turn a real significant topic in the hereafter when the number of road user's increases. There are several models for traffic simulation. Huge amount of traffic cause waiting and accidents. Due to heavy traffic emergency vehicles face adversities.

Cloud computing permits the systems and users to utilize Platform as a Service (PaaS) provider offer several environments to users for development of applications. The user can develop applications according to their requirements. Infrastructure as a Service (IaaS) that provides virtualized computing resources over the Internet, and Software as a Service (SaaS) provides software or application on the internet and customer used these, with no knowledge of development or maintenance [3]. Therefore, Sensor-Cloud base is seemly popin recent years that can offer unfold and elastic program for various supervising and holding diligences. 


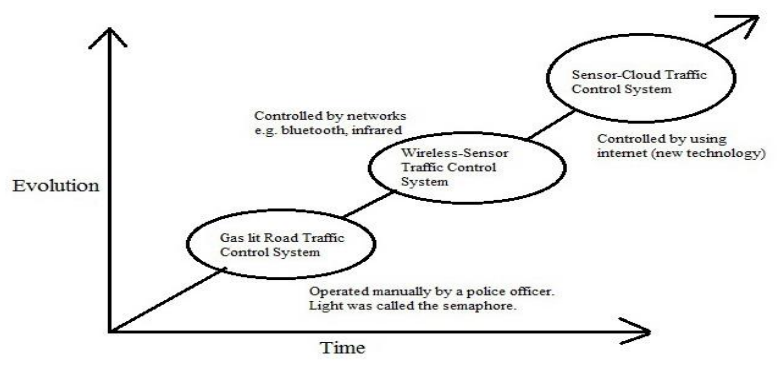

Figure 1. Evolution of Road Traffic Control System

A gas lit traffic control system is a manually operated by a police officer. The use of this system is very difficult due to burst. Nowadays, Wireless Sensor Network is used of controlling the traffic. Wireless sensor network is constructed of nodes. Sensor nodes basically sense data, collect data from other nodes then process that data and then transmit this collected data to the base station. It is proved that node require much power or energy to transmit data. The main concern is to save power to increase the life of sensor network. Wireless sensor network applications used in healthcare, military, environment monitoring, and manufacturing [4]. Due to the limitations of WSNs in terms of memory, energy, computation, communication and scalability [5]. On that point demand for a mighty and scalable high performance computing for treating and storing of the WSN data.

Sensor-Cloud Infrastructure i.e. integrated version of Wireless Sensor Networks and Cloud Computing [6]. A large number of sensor data easily gather, access, process, store, share, and search for using Sensor-Cloud [7]. Sensor-cloud will be placed at a particular space ahead the junctions which will notice the fastness and voice of siren at a specific doorway. On the foundation of the two junctions will be capable to downplay the traffic fall by inter-communication therefore allotting the right time for red and green lights then emergency vehicles can go quickly [8].

Table 1. Key attributes Differentiating Old, Nowadays and Farther Road Traffic Control System

\begin{tabular}{|c|c|c|c|}
\hline $\begin{array}{c}\text { Controlling } \\
\text { Technology } \\
\text { Key Attributes }\end{array}$ & $\begin{array}{c}\text { Old Traffic } \\
\text { Control System }\end{array}$ & $\begin{array}{c}\text { Nowadays Traffic Control } \\
\text { System }\end{array}$ & $\begin{array}{c}\text { Farther Traffic } \\
\text { Control System }\end{array}$ \\
\hline Methods & Gas lit system & Wireless Sensor Network & $\begin{array}{c}\text { Sensor-Cloud } \\
\text { Network }\end{array}$ \\
\hline Power Management & $\begin{array}{c}\text { Dependent on } \\
\text { human power }\end{array}$ & $\begin{array}{c}\text { Do not have defined ability } \\
\text { informants }\end{array}$ & $\begin{array}{c}\text { Not dependent on } \\
\text { load }\end{array}$ \\
\hline Scalability & No & Limited Networks & Multiple Networks \\
\hline $\begin{array}{c}\text { Network } \\
\text { Pronnectivity and }\end{array}$ & No & Dynamic & $\begin{array}{c}\text { Static } \\
\text { Dynamic }\end{array}$ \\
\hline Scheduling & No & $\begin{array}{c}\text { Power management and } \\
\text { sensor resource management }\end{array}$ & $\begin{array}{c}\text { Support job and } \\
\text { service migration }\end{array}$ \\
\hline Performance & Less & Limited & High \\
\hline Robustness & $\begin{array}{c}\text { Limited, failed } \\
\text { task are restarted }\end{array}$ & $\begin{array}{c}\text { fixed, broken projects are } \\
\text { restarted }\end{array}$ & secure \\
\hline $\begin{array}{c}\text { Virtualization } \\
\text { Support }\end{array}$ & No & Yes & Yes \\
\hline Elasticity & No & modified & inexhaustible \\
\hline
\end{tabular}




\section{Existing Traffic Control Systems}

\subsection{Applied Research on Traffic Information Collection system}

The distributed treatment of traffic information collection system is realized. In [9] paper author discussed the essential troubles in the effectuation and reffered settlement schemes. This project used in working clients power, net analysis situs planning and time synchronization among nodes.

\subsection{Platoon-Based Self-Scheduling for Real-Time Traffic Signal Control}

Self-scheduling collects incoming vehicles into critical clusters. Author proposes [10] unfolded conclusion insurances that besides integrate look-ahead of upcoming vehicle platoons. The simulation effect show that the gain of this access is simple queue solving. The formation of "green waves" vehicles run through the road network without halting and amending overall traffic runs.

\subsection{Intelligent Traffic Control Unit}

The Intelligent Traffic Control Unit focuses on three areas-Ambulance, Priority vehicles and Density control [11]. In Ambulances radio frequency identification concept is applied to fix the Ambulances track Green. The outcomes distinctly state that gamiest priority is granted to the ambulance. Secondly in priority vehicles infrared transmitter and receiver are used to make the vehicle track Green. In the third part IR and photodiodes are used in the line of sight to detect the density at the traffic signal.

\subsection{Automatic Daytime Road Traffic Control and Monitoring System}

This theme [12] suggests a method for accurately calculating the routine of vehicles on a route at daylight. The running aims are evoked from a frame-differencing algorithm and the data from grain unit members. The algorithm acts good below hard road traffic conditions such as traces, flora and big trucks. The most significant trinket of the aimed method is the vestiges handling utilizing sole strength of B\&W icons and top hat shifts.

\subsection{Design of Adaptive Road Traffic Control System}

This system based on UML. Author provides this proficiency for manipulating the traffic in main road network utilizing signs [13]. These signs are mechanically moderated aside sensors. To afford well advancement to vehicles through the road network these detectors coordinates the operation of the traffic signals in the entire area. The signal timing varies throughout the day while coordinating all the signals. It withdraws the addiction on less spoiled schemes on sign designs.

\subsection{Priority Based Traffic Lights Controller}

Author presented a vehicle sensing and active traffic signal time handling is used in priority based traffic light controller system [14]. The project is also designed to follow international standards for traffic light operations and control over multiple intersections. Both single and multiple intersections are dynamically adaptive to traffic conditions in these techniques. 
Table 2. Surviving Technologies and Key Characteristics

\begin{tabular}{|c|c|}
\hline Existing Technologies & Key Feature \\
\hline $\begin{array}{c}\text { Priority Based Traffic } \\
\text { Lights Controller }\end{array}$ & $\begin{array}{c}\text { Used for robotic gate opening, VIP vehicles, GPS } \\
\text { navigation system. }\end{array}$ \\
\hline $\begin{array}{c}\text { Applied Research on } \\
\text { Traffic Information } \\
\text { Collection System }\end{array}$ & $\begin{array}{c}\text { Voltage diligences: High degree AC Voltage, vehicle tire } \\
\text { pressure, planes, ships potential troubles supervising before } \\
\text { their navigate. }\end{array}$ \\
\hline $\begin{array}{l}\text { Intelligent Traffic } \\
\text { Control Unit }\end{array}$ & $\begin{array}{c}\text { This system uses the microcontroller to download } \\
\text { registered data, update easy holdups, delete storage etc. }\end{array}$ \\
\hline $\begin{array}{c}\text { Platoon-Based Self- } \\
\text { Scheduling for Real-Time } \\
\text { Traffic Signal Control }\end{array}$ & $\begin{array}{c}\text { Performance of composite operations in active } \\
\text { surroundings manages. }\end{array}$ \\
\hline $\begin{array}{l}\text { Design of Adaptive } \\
\text { Road Traffic Control } \\
\text { System }\end{array}$ & $\begin{array}{c}\text { This system uses the UML. UML is the standard visual } \\
\text { modelling terminology which proposes an extended lot of } \\
\text { plots for modelling. }\end{array}$ \\
\hline $\begin{array}{c}\text { Automatic Daytime } \\
\text { Road Traffic Control and } \\
\text { Monitoring System }\end{array}$ & $\begin{array}{c}\bullet \text { The varieties of measurements that can be achieved } \\
\text { with cameras. }\end{array}$ \\
\hline
\end{tabular}

\section{Conclusion}

In this paper the role of Sensor-cloud in the setting of various living methods in road traffic control system is hashed out. Cloud Computing is development of these engineerings and has announced not to substitute any living technology. Each technology has its possess position and dissimilar technologies demand to mix unitedly in the IT environments. Sensor-Cloud enables the sensor information to be categorised, laid in and treated in such a style that it turns price-efficient, time usable and easily approachable . Sensor-cloud signifies to supply summed features and results to the problems that obsess these technologies. The opportunities of implementing the technology to treat more composite spots of traffic control system.

\section{References}

[1] C. Kim and Y. S. Hong, "Traffic Signal Using Smart Agent System," American Journal of Applied Sciences, (2008), pp. 1487-1493.

[2] L. Okponglo, "Design and Development of Micro-Controller Based Traffic System Using Image Processing Techniques" University of Ghana, published in ICAST, 2012 IEEE $4^{\text {th }}$ International Conference.

[3] J. Srinivas, K. V. S. Reddy, Dr. A. M. Qyser, "Cloud computing basics," International journal of advanced research in computer and communication engineering, vol. 1, no. 5, (2012) July, pp. 343-347.

[4] G. Simon, G. Balogh, G. Pap et. al., "Sensor network-based counter sniper system," in Proceedings of the 2nd International Conference on Embedded Networked Sensor Systems (SenSys '04), Baltimore, Md, USA, (2004) November, pp. 1-12.

[5] J. Yick, B. Mukherjee and D. Ghosal, "Wireless Sensor Network Survey", Elsevier, (2008).

[6] K. T. Lan, "What's NExT? Sensor+Cloud", in Proceeding of 7 the International workshop on Data Management for Sensor networks, ACM Digital Library, ISBN: 978 -1-4503-0416-0, (2010).

[7] H. T. Dinh, C. Lee, D. Niyato, and P. Wang "A Survey of Mobile Cloud Computing, Architecture, Applications, and Approaches Wireless Communications and Mobile Computing" Wiley Online Library, (2011).

[8] http://telematicswire.net/c-dac-launches-witrac-indias-first-wireless-traffic-controller-system. 
[9] X. Chen, J. Zhang, S. Qian and P. Xu, "Applied Research on Traffic Information Collection Based on Wireless Sensor Networks", Elsevier 2012 International Conference on Future Electrical Power and Energy Systems.

[10] X. F. Xie, J. G. Barlow, S. F. Smith and Z. B. Rubinstein, "Platoon-Based Self-Scheduling for RealTime Traffic Signal Control", IEEE International Conference on Intelligent Transportation Systems (ITSC), Washington, DC, USA, (2011).

[11] S. Jaiswal, T. Agarwal, A. Singh and Lakshita, "Intelligent Traffic Control Unit", International Journal of Electrical, Electronics ISSN No. (Online), 2277-2626 and Computer Engineering, vol. 2, no. 2, (2013), pp. 66-72.

[12] P. F. Alcantarilla, M. A. Sotelo and L. M. Bergasa, "Automatic Daytime Road Traffic Control and Monitoring System" Intelligent Transportation Systems, 2008. ITSC 2008. 11th International IEEE Conference on 12-15 Oct, (2008), Page: 944-949.

[13] K. Ranjini, A. Kanthimathi and Y. Yasmine, "Design of Adaptive Road Traffic Control System through Unified Modeling Language" International Journal of Computer Applications (0975 - 8887), vol. 14, no. 7, (2011) February.

[14] K. R. Shruthi and K. Vinodha, "Priority Based Traffic Lights Controller Using Wireless Sensor Networks", International Journal of Electronics, Signals, and Systems (IJESS) ISSN: 2231- 5969, vol. 1 Iss. 4, (2012).

\section{Author}

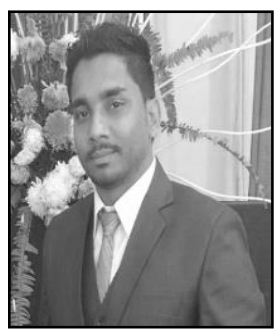

Kapil Kumar, Born on March 41993 in Nakodar city District Jalandhar Punjab India. Completed his B Tech (CSE) from CTIT Shahpur Jalandhar in year 2013 and Pursuing M.Tech in computer Science and Engineering GNDU Regional Campus Jalandhar, Punjab. Area of interest in technology is Cloud Computing, Traffic Control of Cloud Computing, Sensor Cloud. Many research papers have been published of the author in the different conferences like IEEE, International Conferences and different Journals. Looking forward to go for Doctorate in the same field to continue his research. 
International Journal of Grid Distribution Computing Vol. 8, No. 3, (2015) 